\title{
Treatment of Infected Total Knee Arthroplasty
}

\author{
Chul-Won $\mathrm{Ha}, \mathrm{MD}^{1,2}$ \\ Departments of ${ }^{1}$ Orthopaedic Surgery and ${ }^{2}$ Health Sciences and Technology, Stem Cell \& Regenerative Medicine Institute, Samsung Medical Center, Sungkyunkwan \\ University School of Medicine, Seoul, Korea
}

Total knee arthroplasty (TKA) is one of the most commonly performed surgical procedures in the field of orthopedics. The increasing frequency of TKA in the growing elderly population has resulted in a rise in the incidence of postoperative infection ${ }^{1,2}$. Infection after TKA is a significant condition that may lead to a number of complications, and the management of infected TKA is often challenging. The theme of this issue of Knee Surgery \& Related Research (KSRR) is the treatment of infected TKA. The current issue contains four articles including one review article and three original articles on this theme. The review article is on the epidemiology, diagnosis and treatment of culture-negative periprosthetic joint infection. The original article by Son et al. described the efficacy of open debridement and polyethylene exchange (ODPE) in strictly selected patients with infection after TKA. Another original article by Juul et al. ${ }^{3)}$ reported on the use of a new knee prosthesis as an articulating spacer in two-stage revision of infected TKA. The other original article by Shon et al. ${ }^{4}$ compared hemodynamic and hematologic changes between the TKA group and the revision group.

Management of infected TKA is a challenge to both patients and surgeons, and identification of microorganisms is important for proper treatment. However, culture-negative rates are known to be high ${ }^{1,2,5)}$, which makes infected TKA more difficult to treat. Even if a culture is negative, antibiotics can help eradiataion of infection. As the Staphylococcus species are the most common

Correspondence to: Chul-Won Ha, MD

Department of Orthopaedic Surgery, Samsung Medical Center, Sungkyunkwan University School of Medicine, 81 Irwon-ro, Gangnam-gu, Seoul 06351, Korea

Tel: +82-2-3410-0275, Fax: +82-2-3410-0061

E-mail: chulwon.ha@gmail.com

This is an Open Access article distributed under the terms of the Creative Commons Attribution Non-Commercial License (http://creativecommons.org/licenses/by-nc/4.0/) which permits unrestricted non-commercial use, distribution, and reproduction in any medium, provided the original work is properly cited. infecting organism in infected TKA, many surgeons choose cephalosporins. Vancomycin has been suggested as an alternative antibiotic in situations with increased chances of methicillinresistant Staphylococcus aureus infections. I believe the review article in this issue of KSRR on the epidemiology, diagnosis and treatment of culture-negative periprosthetic joint infection will provide valuable information to the readers.

In addition to antibiotic treatment, surgical options play an important role regardless of the results of culture. ODPE, onestage revision, and two-stage revision can be the options. ODPE is generally performed for early infections, but the results vary widely. The original article by Son et al. in this issue of $K S R R$ described the efficacy of ODPE in strictly selected patients with infection after TKA. They performed ODPE within five days after the onset of symptoms in early postoperative infections and acute hematogenous infections and showed a high treatment success rate of $88 \%$ and satisfactory functional scores. The authors recommend that ODPE be performed in patients with less than 5 days of duration of symptom in early postoperative infections and acute hematogenous infections.

In chronic infection after TKA, two-stage revision is the most popular surgical option. Static antibiotics-impregnated cement spacers and articulating antibiotic spacers can be used. Several studies have proven the benefits of articulating spacers over static spacers in the treatment of infected $\mathrm{TKA}^{6-8)}$. Since range of motion (ROM) exercises are encouraged in patients with an articulating spacer, the final ROM after revision TKA is usually greater when treated with articulating spacers than with static spacers. In addition, knee function during treatment is superior with articulating spacers than with static spacers ${ }^{9,10)}$. In this issue of $K S R R$, Juul et al. ${ }^{3)}$ report the use of a new femoral component as the articulating spacer for two-stage revision of infected TKA. The eradication rate was $82 \%$ and the authors demonstrated increased ROM and function scores. 
After one-stage or two-stage revision in infected TKA, more complications can emerge than after primary TKA because of the prolonged operation time, extensive joint exposure, larger amount of bone defect, and extensive debridement of soft tissues $^{11,12)}$. Also, blood transfusion rates are higher after revision of infected TKA, which often leads to increased postoperative complication ${ }^{13-15)}$. Shon et al. ${ }^{4)}$ article in this issue reports that the transfusion rate was higher in the revision TKA group (20\%) than in the primary TKA group (12\%), and the postoperative blood loss and transfusion volume were also greater in the revision group. The authors emphasize that surgeons should pay more attention to patients' postoperative general condition to reduce postoperative complications.

The current issue has mainly focused various considerations related to the treatment of infected TKA. Further research on the treatment of infected TKA is required in order to minimize complications and optimize clinical outcomes.

\section{References}

1. Berbari EF, Marculescu C, Sia I, Lahr BD, Hanssen AD, Steckelberg JM, Gullerud R, Osmon DR. Culture-negative prosthetic joint infection. Clin Infect Dis. 2007;45:1113-9.

2. Parvizi J, Ghanem E, Menashe S, Barrack RL, Bauer TW. Periprosthetic infection: what are the diagnostic challenges? J Bone Joint Surg Am. 2006;88 Suppl 4:138-47.

3. Juul R, Fabrin J, Poulsen K, Schroder HM. Use of a new knee prosthesis as an articulating spacer in two-stage revision of infected total knee arthroplasty. Knee Surg Relat Res. 2016;28:239-44.

4. Shon OJ, Lee DC, Ryu SM, Ahn HS. Comparison of difference in hematologic and hemodynamic outcomes between primary total knee arthroplasty and revision of infected total knee arthroplasty. Knee Surg Relat Res. 2016;28:130-6.

5. Ghanem E, Parvizi J, Clohisy J, Burnett S, Sharkey PF, Barrack R. Perioperative antibiotics should not be withheld in proven cases of periprosthetic infection. Clin Orthop Relat Res. 2007;461:44-7.
6. Emerson RH Jr, Muncie M, Tarbox TR, Higgins LL. Comparison of a static with a mobile spacer in total knee infection. Clin Orthop Relat Res. 2002;(404):132-8.

7. Fehring TK, Odum S, Calton TF, Mason JB. Articulating versus static spacers in revision total knee arthroplasty for sepsis: the Ranawat Award. Clin Orthop Relat Res. 2000; (380):9-16.

8. Freeman MG, Fehring TK, Odum SM, Fehring K, Griffin WL, Mason JB. Functional advantage of articulating versus static spacers in 2-stage revision for total knee arthroplasty infection. J Arthroplasty. 2007;22:1116-21.

9. Shaikh AA, Ha CW, Park YG, Park YB. Two-stage approach to primary TKA in infected arthritic knees using intraoperatively molded articulating cement spacers. Clin Orthop Relat Res. 2014;472:2201-7.

10. Park SJ, Song EK, Seon JK, Yoon TR, Park GH. Comparison of static and mobile antibiotic-impregnated cement spacers for the treatment of infected total knee arthroplasty. Int Orthop. 2010;34:1181-6.

11. Tahmasebi MN, Bashti K, Ghorbani G, Sobhan MR. Intraarticular administration of tranexamic acid following total knee arthroplasty: a case-control study. Arch Bone Jt Surg. 2014;2:141-5.

12. Aguilera X, Videla S, Almenara M, Fernandez JA, Gich I, Celaya F. Effectiveness of tranexamic acid in revision total knee arthroplasty. Acta Orthop Belg. 2012;78:68-74.

13. Prasad N, Padmanabhan V, Mullaji A. Blood loss in total knee arthroplasty: an analysis of risk factors. Int Orthop. 2007;31:39-44.

14. Frisch NB, Wessell NM, Charters MA, Yu S, Jeffries JJ, Silverton $\mathrm{CD}$. Predictors and complications of blood transfusion in total hip and knee arthroplasty. J Arthroplasty. 2014; 29(9 Suppl):189-92.

15. Hart A, Khalil JA, Carli A, Huk O, Zukor D, Antoniou J. Blood transfusion in primary total hip and knee arthroplasty: incidence, risk factors, and thirty-day complication rates. J Bone Joint Surg Am. 2014;96:1945-51. 